серого чугуна и соизмерима с некоторыми марками углеродистой конструкционной стали. Исследованные механические свойства и получен- ные механические характеристики возможно использовать при расчете и проектировании изделий из ППС при различных видах сопротивления.

P. Dorodov, M. Kudrin, A. Kostin, V. Nikolaev

\title{
INVESTIGATION INTO PHYSICAL AND MECHANICAL PROPERTIES OF POLYMERIC SAND USED FOR COWSHED FLOORING
}

Key words: flooing; stall; polymeric sand; mechanical characteristics; strength; hardness; plastic flow deformation; compression; bending; impact; fatigue.

\section{Authors' personal details}

1. Dorodov Pavel, Doctor of Technical Sciences, Professor at the Department of Theoretical Mechanics and Strength of Materials, Izhevsk State Agricultural Academy, 11, Studencheskaya St., Izhevsk, Udmurt Republic, 426069, e-mail: pvd80@mail.ru.

2. Kudrin Mikhail, Candidate of Agricultural Sciences, Associate Professor of the Department of Private Farm Animal Production, Izhevsk State Agricultural Academy, 11, Studencheskaya St., Izhevsk, Udmurt Republic, 426069.

3. Kostin Alexander, Candidate of Technical Sciences, Associate Professor of the Department of Theoretical Mechanics and Strength of Materials, Izhevsk State Agricultural Academy, 11, Studencheskaya St., Izhevsk, Udmurt Republic, 426069, e-mail: kostin13@mail.ru.

4. Nikolaev Vladimir, Candidate of Agricultural Sciences, Associate Professor of the Department of Private Farm Animal Production, Izhevsk State Agricultural Academy, 11, Studencheskaya St., Izhevsk, Udmurt Republic, 426069.

Physical and mechanical properties of the polymeric sand used as floor covering in cattle stalls were investigated. Samples of the polymeric sand were tested under static and dynamic stress, an impact test was done, mechanical characteristics were measured, and the material structural efficiency was evaluated. The polymeric sand tile appeared strong, reliable and durable material. The study material exhibited viscoelasticity. The polymeric sand samples

(C) Дородов П.В., Кудрин М.Р., Костин А.В., Николаев В.А. demonstrated impact viscosity in the range $242,3-$ $548,3 \mathrm{~kJ} / \mathrm{m}^{2}$. The figure was $3,5-13,7$ times higher than that of gray cast iron and was comparable with some classes of carbon structural steel. Mechanical properties of the polymeric sand were analysed. The characteristics revealed in the analysis can be used in dimensioning and designing products made from polymeric sand under various strength indices.

УДК 631.316 .5

DOI: $10.31563 / 1684-7628-2019-52-4-123-129$

А.А. Михайлин, В.П. Максимов

\section{ОЦЕНКА ЭФФЕКТИВНОСТИ ОБРАБОТКИ БОГАРНЫХ СКЛОНОВЫХ ЗЕМЕЛЬ В ЮЖНЫХ РАЙОНАХ РОСТОВСКОЙ ОБЛАСТИ ИННОВАЦИОННЫМ ГЛУБОКОРЫХЛИТЕЛЕМ ГНЧ-0,6М}

Ключевые слова: глубокорыхлитель; чизель; переуплотнение; богарные земли; склон; аккумуляция влаги; урожайность.

Введение. За последние 30 лет в Российской Федерации переуплотнение пахотных земель превысило 10 млн га. Причиной этого являются многократные проходы энергонасыщенной тех- ники по полям. За последние 40 лет под воздействием тяжелых машин почвы стали плотнее на $20 \%$ [1]. Под воздействием техногенной нагрузки возникает накопление остаточных де- 
формаций уплотнения не только в пахотном, но и в подпахотном слоях почвы. В результате переуплотнения образуется «плужная подошва», что препятствует проникновению воды вглубь почвы в дождливую погоду и при больших поливных нормах. Происходит нерациональная потеря влаги на испарение при засухе и снижение инфильтрационных показателей к поверхностному стоку на склоновых землях, нарушается капиллярный приток влаги из более глубоких слоев к поверхности. Очевидно, что для реализации планов по повышению продуктивности пахотных земель России необходимо создание новых технических средств, обеспечивающих обработку почвы на глубину до 80 см при снижении энергоемкости их функционирования.

Цели и задачи исследования. Исследования показывают, что в результате переуплотнения земель образуется подпахотный уплотненный слой на глубине 25...60 см, плотность кото-

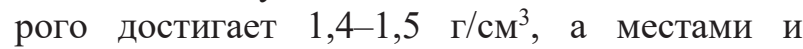

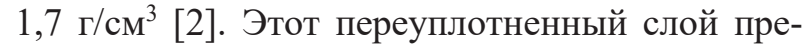
пятствует проникновению в почву воды и воздуха, приводит к снижению коэффициента фильтрации и воздухопроницаемости в 5-15 раз [1]. В такой почве практически прекращаются все почвообразовательные процессы. По данным А.Г. Бондарева [3, 4], Е.Н. Лиманского [5], чем сильнее уплотняется почва при одном и том же виде и характере техногенного воздействия, тем медленнее происходит ее естественное разуплотнение. Проблема продуктивности равнинных и отчасти склоновых земель исследовалась многими учёными: А.И. Бараевым, А.А. Коршиковым, Н.А. Ивановой, И.М. Пановым, В.В. Бледных, П.Г. Свечниковым, А.В. Бауковым, В.И. Ветохиным и др. На данном этапе развития агротехники разработаны многие приемы по задержанию талых вод и атмосферных осадков на склонах. Среди них: террасирование, устроение естественных преград на обрабатываемом склоне, мульчирование, щелевание и др. Однако все они либо очень дороги и трудоемки, либо малоэффективны. В моделировании явлений переноса влаги в почве используют понятие порозности, которая непосредственно зависит от плотности и физико-механических свойств почвы.

Целью исследования является повышение продуктивности пахотных земель путем восстановления их плодородия посредством глубокого безотвального рыхления и оптимизации воздействий на элементы конструкции глубокорыхлителя.

Задачи исследований: разработка ресурсосберегающей технологии обработки склоновых земель, предусматривающей глубокое рыхле- ние, направленное на снижение эрозионных процессов на орошаемых и богарных землях; разработка нового технического решения глубокорыхлителя; оценка количественных показателей урожайности в результате применения предлагаемых орудия и технологии.

Условия, материалы и методы исследований. Создание необходимых условий для водопроницаемости возможно соответствующими рабочими органами за счет механического крошения переуплотненных горизонтов на почвенные комки соответствующих размеров. Интегральным показателем экономических функций почвы является биологическая продуктивность - урожай, которая определяется главным образом применением различных видов мелиораций. В рассматриваемом случае имеет место мелиорация переуплотненных склоновых земель, которые после рыхления получает новую эволюцию и возможность реализации новых технологических процессов, обеспечивающих глобальную цель повышения урожайности. Исходя из этого, одним из наиболее подходящих технических приемов по качественному улучшению плодородия склоновых земель будет новый способ глубокой безотвальной обработки [6], способствующий аккумуляции атмосферных осадков в толще обрабатываемого слоя до 0,6 м. Это является основой в разработке мелиоративной ресурсосберегающей технологии обработки склоновых земель.

Методы исследований. Применен интегрированный подход к исследованию: проектирование глубокорыхлителя; анализ плотности почвы после рыхления; сравнительный анализ урожайности после применения предлагаемой технологии.

Результаты исследования. На сегодняшний день отсутствуют специализированные способы эффективного возделывания сельскохозяйственных культур на склоновых землях. Вследствие этого нет орудий для основной обработки почвы на основе глубокого рыхления для обработки склоновых земель, направленные на создание устойчивых биоагроценозов на склонах. До сегодняшнего времени отечественными учёными [7-12] и др. не рассматривалось создание эффективных технологий, направленных на обработку склоновых земель, следовательно, не разрабатывались сельскохозяйственные специализированные орудия для глубокой безотвальной обработки склонов или универсальные, применяемые на равнинных участках и с некоторой модификацией на склонах. Таким образом, чизелевание на переуплотнённых склонах необходимо проводить так, чтобы производилось разрыхление переуплотнённых почв без 
оборота пласта, одновременно с аккумулированием внутрипочвенной влаги на склоне.

В текущее время на полях применяются почвообрабатывающие орудия без оборота пласта с глубиной обработки до 40-45 см. Но этого оказывается недостаточно, так как поперечная проекция образующейся области разрыхления является неоптимальной [13].

В рамках исполнения Указа Президента Российской Федерации от 21 июля 2016 г. № 350 «О мерах по реализации государственной научнотехнической политики в интересах развития сельского хозяйства» была разработана конструкция и техническая документация экспериментального орудия для безотвальной глубокой обработки почвы до 0,6 м - глубокорыхлителя навесного чизельного ГНЧ-0,6М (заявка № 2017140567). Глубокорыхлитель ГНЧ-60М изготовлен в металле и испытан в производственных условиях [13, 14]. На рисунке 1 показаны: рама
(1); стойка (2); смежные рыхлящие грани (3); наральник (4); почвоподъёмные пластины (грунтоподъёмники) (5); шарнир (6); культиваторная лапа (7). Установка исследуемых элементов системы - деформаторов орудия - приведена на рисунке 2.
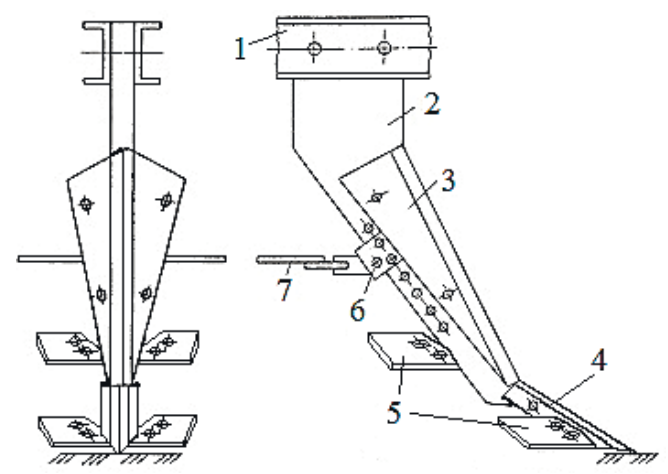

Рисунок 1

Рабочий орган универсального глубокорыхлителя навесного чизельного типа ГНЧ-0,6М

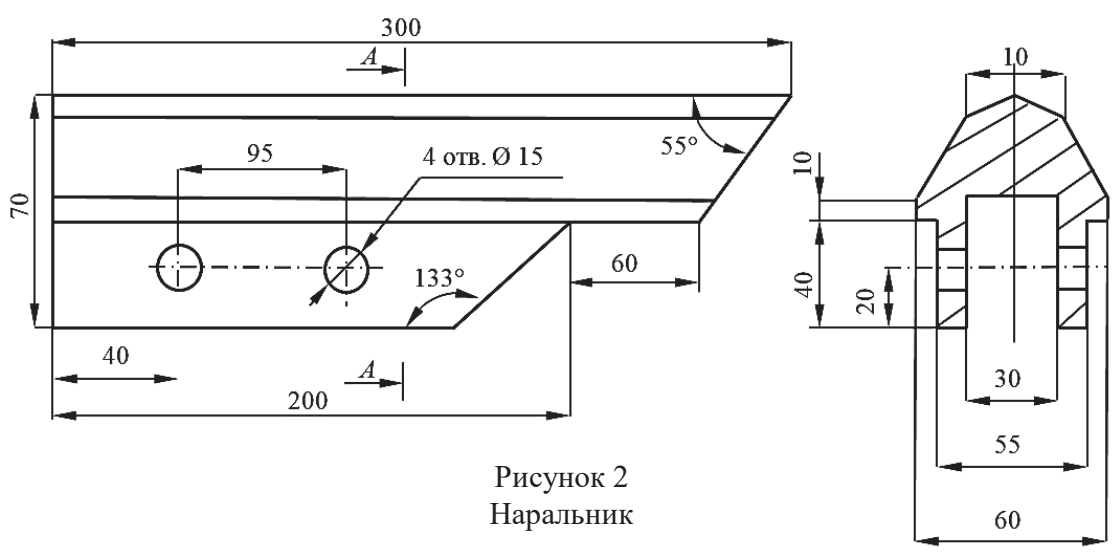

Отличительной особенностью разработанного орудия является формирование оптимальной для корневой системы растений зоны разрыхления, что достигается соответствующими геометрическими и топологическими параметрами формы стойки глубокорыхлителя, дополнительных грунтоподъемников и наральника, устанавливаемых на стойке орудия.

В результате проведенных нами исследований установлено, что форма стойки глубокорыхлителя в поперечной проекции должна оставаться не сглаженной, а ломаной, как на прототипе. Это необходимо для повышения качества крошения разуплотняемого пласта. Почва на глубине 30-60 см зачастую имеет очень высо-

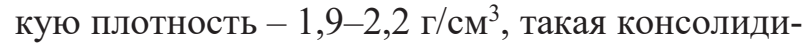
рованность почвенных комочков обеспечивает целостность большим кускам земли, отломанным от разуплотняемого пласта, попросту скользить по гладкому профилю стоек без разрушения. Это приводит к их вывороту на дневную поверхность кусков из сверхпереуплотнённой почвы, которые находились в нижних гори- зонтах разуплотняемого слоя. Использование стойки с ломаным профилем позволяет увеличить разрушающее воздействие на сверхплотные отдельные глыбы, которые будут упираться в переходные углы стойки, что способствует возникновению в комьях дополнительных разрушающих деформаций. При этом углы развала с фронтальной стороны стойки не должны создавать излишнего налипания на стойку, а фронтальная часть стойки должна быть заострена.

В процессе рыхления первая задействованная часть - это наральник. Практически у всех глубокорыхлителей он имеет форму долота. Но для глубокорыхлителей, рыхлящих на глубину 50 см и более, такая форма наральника является очень энергозатратной - резко повышается тяговое сопротивление при рыхлении почв. Также, согласно теории резания грунта, резание грунтов долотом позволяет получать стружку, которая наползает по фронтальной плоскости долота, что не является в данном случае необходимым критерием. В условиях сплошной переуплотнённой среды с большой пригрузкой не 
нужно получать скольжение подрезаемого пласта - необходимо в нижней части, на глубине 45-60 см, разуплотняемого слоя производить трещины, то есть раскалывать пласт на отдельные куски, которые, пытаясь проскользить вверх по наклонной фронтальной плоскости грунтоподьёмника, дополнительно крошились бы, вступая во взаимодействие с его острыми гранями, а не скользили по гладкой поверхности.

Заострённый носок наральника также способствует снижению тягового сопротивления при обработке почвы и лучше создаёт гребнистый профиль борозды. Исходя из изложенного нами, был спроектирован наральник с заострённой носовой частью и гранённой поверхностью атаки, как показано на рисунке 2. Грунтоподъёмники имеют форму трапеции, у которой наклонная сторона внутренняя, обращённая к стойке, длина грани ВC 210 мм. Ширина грунтоподъёмника по наружной стороне равна 140 мм, ширина по внутренней стороне грутоподъёмника - грань ДЕ - 105 мм (рисунок 3). Толщина грунтоподъёмников 7 мм. Грань $A B D E$ грунтоподъёмник является внутренней (медиальной) и прилежит к стойке орудия.

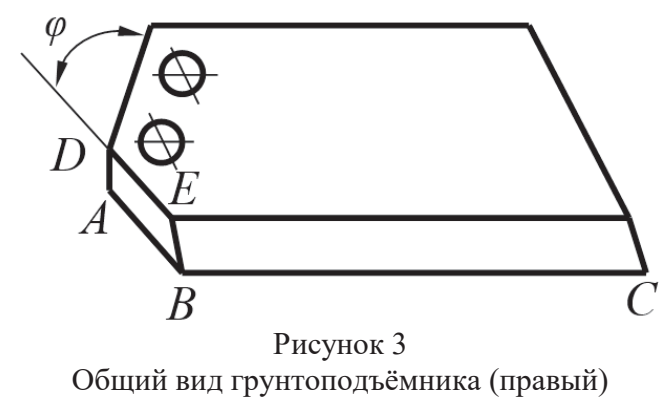

Исходя из того, что рыхление должно происходить на глубину до 60 см, то дополнительные рыхлящие элементы системы деформаторов стойки глубокорыхлитлеля, расположенные перпендикулярно вертикальной продольной оси стойки, будут испытывать значительное давление разрыхляемой среды и пригрузку, металлические пластины установлены по бокам стойки под углом 40-50 к горизонту. Крепится каждый

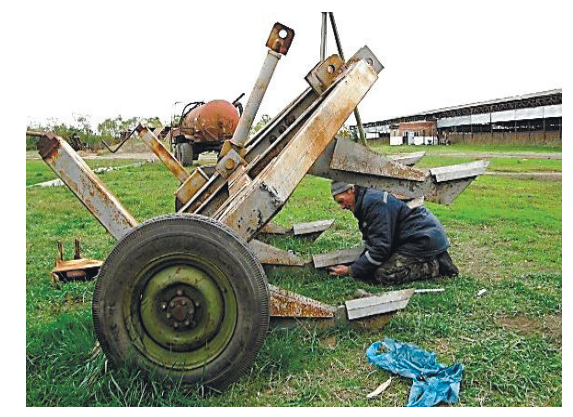

Рисунок 4

Установка грунтоподъёмников на стойки ГНЧ-0,6М грунтоподъёмник двумя винтами под потай к крепёжной лапе, приваренной к стойке глубокорыхлителя. Исследования проводились в период 2016-2018 гг. на полях ФГБУ ВО Донской УНПК «Учхоз Зерновое» Донского государственного аграрного университета, в Зерноградском районе Ростовской области. Основной почвенной разностью этого региона являются карбонатные чернозёмы, в которых содержание гумуса 3,2-3,3 \%. Среднегодовое значение по количеству осадков 560-600 мм. Средняя температура воздуха 9,6 ${ }^{\circ} \mathrm{C}$. Влажность воздуха в среднем 56 \%. Обрабатываемое поле имеет уклон до $5^{\circ}$.

Глубокая безотвальная обработка проводилась в октябре 2016 г. Натурный эксперимент проводился при основной глубокой обработке почвы на глубину 0,55-0,6 м на фоне возделывания ярового ячменя. Площадь опытного участка составила 16 га, контроль - 70 га.

На рисунке 5 показаны два сравниваемых вида обработки, слева - глубокое рыхление на глубину 55-60 см (опыт), справа - вспашка + дискование (контроль). Результаты исследований по биологической урожайности в 2017 году показаны на контроле в таблице 1 и опыте в таблице 2 (взятие проб 03.06.2017 г.). На рисунке 6 показан ячмень на контроле 06.06.2017 г. На рисунке 7 показано развитие ячменя на опытном участке на 06.06.2017 г.

Проведенные натурные исследования показали, что глубокое безотвальное рыхление экспериментальным глубокорыхлителем чизельного типа ГНЧ-0,6М увеличило биологическую урожайность выращиваемых посевных культур в 2017 году на примере ярового ячменя до $22,10 \%$ и повышает массу соломы на 24,18 \% по сравнению с контролем. В следующем, 2018 году на этом же поле проводились замеры биологической урожайности озимой пшеницы. Исследовалось влияние последействия глубокой обработки экспериментальным чизелем ГНЧ0,6М на урожайность посевных культур. Результаты исследований по биологической урожайности в 2017 году показаны на контроле в таблице 3 и опыте в таблице 4 (взятие проб 04.06.2018 г.).

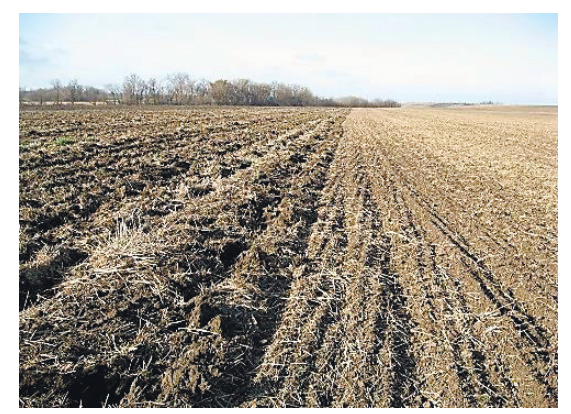

Рисунок 5

Опытный и контрольный участки, ноябрь 2016 г. 
Таблица 1 Яровой ячмень (контроль), 2017 г.

\begin{tabular}{|c|c|c|c|c|c|}
\hline Показатель & $1\left(0,25 \mathrm{M}^{2}\right)$ & $2\left(0,25 \mathrm{M}^{2}\right)$ & $3\left(0,25 \mathrm{M}^{2}\right)$ & $4\left(0,25 \mathrm{M}^{2}\right)$ & Сумма $\left(1 \mathrm{~m}^{2}\right)$ \\
\hline Кол-во растений с корнем, шт. & 55 & 63 & 50 & 70 & 238 \\
\hline Масса соломенной части с колосом, г & 290 & 335 & 279 & 390 & 1294 \\
\hline Кол-во продуктивных колосьев, шт. & 135 & 214 & 181 & 172 & 702 \\
\hline Масса чистого зерна с колосьев, г & 112,96 & 119,03 & 108,94 & 130,65 & 471,58 \\
\hline Масса одного колоса, г & 0,51 & 0,60 & 0,48 & 0,64 & Средн. 0,58 \\
\hline Масcа 1000 зерен, г & 46,24 & 42,33 & 46,32 & 43,39 & 178,28 \\
\hline Количество зерен в одной повторности, шт. & 2443 & 2812 & 2352 & 3011 & 11059 \\
\hline Кол-во зерен в колосе, шт. & 16 & 14 & 17 & 14 & Средн.15 \\
\hline Масса соломы, г & 210,42 & 224,51 & 171,95 & 253,31 & 860,19 \\
\hline Биологическая урожайность, ц/га & & 47,16 \\
\hline
\end{tabular}

Таблица 2 Яровой ячмень (опыт), 2017 г.

\begin{tabular}{|c|c|c|c|c|c|}
\hline Показатель & $1\left(0,25 \mathrm{M}^{2}\right)$ & $2\left(0,25 \mathrm{M}^{2}\right)$ & $3\left(0,25 \mathrm{M}^{2}\right)$ & $4\left(0,25 \mathrm{~m}^{2}\right)$ & Сумма $\left(1 \mathrm{~m}^{2}\right)$ \\
\hline Кол-во растений с корнем, шт. & 57 & 70 & 63 & 75 & 265 \\
\hline Масса соломенной части с колосом, г & 316 & 430 & 410 & 418 & 1574 \\
\hline Кол-во продуктивных колосьев, шт. & 161 & 216 & 175 & 208 & 760 \\
\hline Масса чистого зерна с колосьев, Г & 127,83 & 146,24 & 135,68 & 166,11 & 575,86 \\
\hline Масса одного колоса, г & 0,74 & 0,70 & 0,73 & 0,71 & Средн. 0,72 \\
\hline Масса 1000 зерен, г & 49,11 & 47,73 & 45,56 & 53,88 & 196,28 \\
\hline Количество зерен в одной повторности, шт. & 2603 & 3064 & 2978 & 3083 & 11728 \\
\hline Кол-во зерен в колосе, шт. & 15 & 17 & 16 & 16 & Средн. 16 \\
\hline Масса соломы, $г$ & 227,64 & 283,80 & 254,12 & 302,59 & 1068,15 \\
\hline Биологическая урожайность, ц/га & \multicolumn{4}{|c|}{ ב } & 57,58 \\
\hline
\end{tabular}

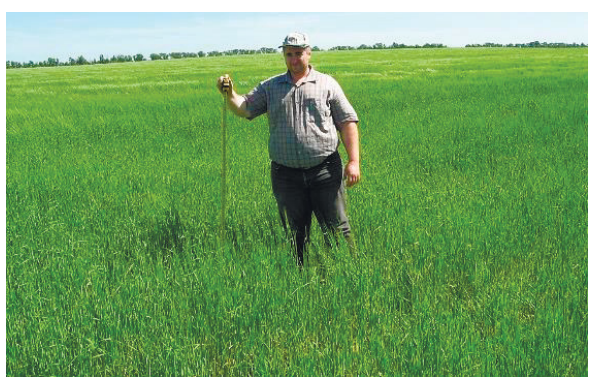

Рисунок 6

Яровой ячмень (контроль), 2017 г.

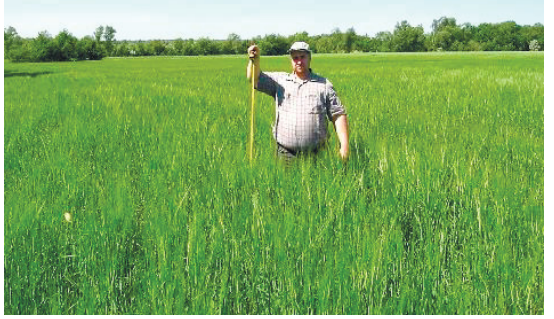

Рисунок 7

Яровой ячмень (опыт), 2017 г.

Таблица 3 Озимая пшеница (контроль), 2017 г.

\begin{tabular}{|c|c|c|c|c|c|}
\hline Показатель & $1\left(0,25 \mathrm{M}^{2}\right)$ & $2\left(0,25 \mathrm{M}^{2}\right)$ & $3\left(0,25 \mathrm{~m}^{2}\right)$ & $4\left(0,25 \mathrm{M}^{2}\right)$ & Сумма $\left(1 \mathrm{~m}^{2}\right)$ \\
\hline Кол-во растений с корнем, шт. & 35 & 67 & 53 & 57 & 212 \\
\hline Масса соломенной части с колосом, г & 289 & 420 & 335 & 339 & 1383 \\
\hline Кол-во продуктивных колосьев, шт. & 135 & 214 & 181 & 172 & 702 \\
\hline Масса чистого зерна с колосьев, г & 93,77 & 130,55 & 124,92 & 102,05 & 451,29 \\
\hline Масса одного колоса, г & 0,73 & 0,60 & 0,68 & 0,63 & Средн. 0,68 \\
\hline Масcа 1000 зерен, Г & 46,24 & 42,33 & 46,32 & 43,39 & Средн. 44,5 \\
\hline Кол-во зерен в одной повторности, шт. & 2028 & 3084 & 2697 & 2352 & 10280 \\
\hline Кол-во зерен в колосе, шт. & 15 & 14 & 15 & 14 & Средн. 15 \\
\hline Масса соломы, г & 189,40 & 254,51 & 212,12 & 226,95 & 904,91 \\
\hline Соотношение солома/зерно & 2,02 & 1,95 & 1,70 & 2,21 & Средн. 1,97 \\
\hline Биологическая урожайность, ц/га & & 45,13 \\
\hline
\end{tabular}

Таблица 4 Озимая пшеница (опыт), 2017 г.

\begin{tabular}{|c|c|c|c|c|c|}
\hline Показатель & $1\left(0,25 \mathrm{M}^{2}\right)$ & $2\left(0,25 \mathrm{M}^{2}\right)$ & $3\left(0,25 \mathrm{M}^{2}\right)$ & $4\left(0,25 \mathrm{M}^{2}\right)$ & Сумма $\left(1 \mathrm{M}^{2}\right)$ \\
\hline Кол-во растений с корнем, шт. & 58 & 68 & 50 & 71 & 247 \\
\hline Масса соломенной части с колосом, г & 330 & 355 & 420 & 279 & 1384 \\
\hline Кол-во продуктивных колосьев, шт. & 161 & 216 & 183 & 169 & 729 \\
\hline Масса чистого зерна с колосьев, г & 124,89 & 147,15 & 112,58 & 135,19 & 519,81 \\
\hline Масса одного колоса, г & 0,74 & 0,69 & 0,78 & 0,61 & Средн. 0,68 \\
\hline Мacca 1000 зерен, г & 49,11 & 47,73 & 45,56 & 43,88 & Средн.46,5 \\
\hline Кол-во зерен в одной повторности, шт. & 2543 & 3083 & 2471 & 3081 & 11178 \\
\hline Кол-во зерен в колосе, шт. & 16 & 15 & 17 & 16 & Средн.16 \\
\hline Масса соломы, г & 212,42 & 272,80 & 277,31 & 230,59 & 993,12 \\
\hline Соотношение солома/зерно & 1,7 & 1,85 & 2,46 & 1,71 & Средн. 1,93 \\
\hline Биологическая урожайность, ц/га & \multicolumn{4}{|c|}{-} & 51,98 \\
\hline
\end{tabular}


Вывод. В результате проведенных исследований последействия глубокого рыхления на глубину 60 см экспериментальным чизелем ГНЧ-0,6М выявлено, что на опытном участке получена биологическая урожайность 51,98 ц/га, что на $13,2 \%$ больше, чем на контроле $(45,13$ ц/га). При этом прибавка урожайности в последующем году на опытном участке снизилась с $22,10 \%$ до 13,2 \%. Отсюда следуют практиче- ские рекомендации: - для поддержания высокой урожайности посевных культур, в зависимости от климатических и почвенных условий места проведения, мелиоративные мероприятия по глубокому рыхлению на глубину до 0,6 м экспериментальным навесным глубокорыхлителем чизельного типа ГНЧ-0,6М следует проводить один раз в два года.

\section{Библиографический список}

1. Доклад о состоянии и использовании земель в 2015 г. [Текст]. М.: Росинформагротех, 2017. 196 с.

2. Михайлин, А.А. Разуплотнение подпахотного слоя почвы в зоне орошения глубокорыхлителем чизельного типа [Текст]: дис. ... канд. техн. наук: 06.01.02 и 05.20.01 / А.А. Михайлин. Новочеркасск, 2003. 123 с.

3. Бондарев. А.Г. Некоторые пути определения оптимальных параметров агрофизических свойств почв [Текст] / А.Г. Бондарев, В.В. Медведев // Теоретические основы и методы определения оптимальных параметров свойств почв: Бюллетень // Почвенный институт им. В.В. Докучаева. М., 1980. С. 85-98.

4. Бондарев, А.Г. Переуплотнение почв сельскохозяйственной техникой, прогноз явления и процессы разуплотнения [Текст] / А.Г. Бондарев, И.В. Кузнецова, П.М. Сапожников // Почвоведение. 1994. № 4. С. 58-64.

5. Лиманский, Е.Н. Рыхлители для безотвальной обработки почв [Текст] // Гидротехника и мелиорация. 1985. № 12. С. 59.

6. Михайлин, А.А. Способ обработки склоновых почв [Текст]. Патент на изобретение RUS 225545029.03 .2002$.

7. Божко, И.В. Разработка комбинированного рабочего органа для послойной безотвальной обработки почвы [Текст] / И.В. Божко, Г.Г. Пархоменко, А.В. Громаков, С.И. Камбулов, В.Б. Рыков // Тракторы и сельхозмашины. 2016. № 8. С. 3-6.

8. Рыков, В.Б. Ресурсосберегающие машинные технологии обработки почвы и технические средства для АПК юга России [Текст] /
В.Б. Рыков // Вестник аграрной науки Дона. 2011. T. 1. № 13. C. 31-38.

9. Рыков, В.Б. Механико-технологическое обоснование технических средств и агрегатов для обработки почвы в условиях засушливого земледелия юга России [Текст]: дис. .... д-ра техн. наук: 05.20.01 / В.Б. Рыков. М., 2001. 340 с.

10. Борисенко, И.Б. Новые технологии обработки почвы [Текст] / И.Б. Борисенко, Е.А. Иванцова, Ю.Н. Плескачев, А.Н. Сидоров // Известия Нижневолжского агроуниверситетского комплекса: Наука и высшее профессиональное образование. 2012. № 1. С. 14-16.

11. Бледных, В.В. Плоскорежущие рабочие органы для качественной обработки почвы [Текст] / В.В. Бледных, П.Г. Свечников, М.М. Мухаматнуров // Научные проекты южно-уральского государственного аграрного университета. Челябинск, 2016. С. 44-47.

12. Мазитов, Н.К. Влагоаккумулирующая техника и технология обработки почвы и посева в условиях Поволжья, Предуралья и Северного Кавказа [Текст] / Н.К. Мазитов, Л.З. Шарафиев // Рекомендации по прорывным решениям по импортозамещению в АПК. Казань, 2016. С. 179.

13. Михайлин, А.А. К вопросу об определении параметров области разрыхления [Текст] / А.А. Михайлин, М.А. Бандурин, С.В. Филонов // Инженерный вестник Дона. 2015. № 4-2 (39).

14. Михайлин, А.А. Влияние технических характеристик орудия на показатели качества глубокого разрыхления орошаемых земель [Текст] / А.А. Михайлин, В.П. Максимов, И.В. Клименко // Научный журнал Российского НИИ проблем мелиорации. 2013. № 3 (11). С. 134-147.

\section{Сведения об авторах}

1. Михайлин Андрей Андреевич, кандидат технических наук, доцент, Федеральное государственное бюджетное образовательное учреждение высшего образования «Южно-Российский государственный политехнический университет (НПИ) имени М.И. Платова», 346428, Российская Федерация, Ростовская обл., г. Новочеркасск, ул. Просвещения, 132, e-mail: 1Andreymih@gmail.com. 
2. Максимов Валерий Павлович, доктор технических наук, профессор, Федеральное государственное бюджетное образовательное учреждение высшего образования «Южно-Российский государственный политехнический университет (НПИ) имени М.И. Платова», 346428, Российская Федерация, Ростовская обл., г. Новочеркасск, ул. Просвещения, 132, e-mail: v_maximov@mail.ru.

При моделировании явлений переноса влаги в почве используют понятие порозности, которая непосредственно зависит от плотности и физико-механических свойств почвы. Создание необходимых условий для водопроницаемости возможно соответствующими рабочими органами за счет механического крошения переуплотненных горизонтов на почвенные комки соответствующих размеров. Интегральным показателем экономических функций почвы является биологическая продуктивность - урожай которая определяется главным образом применением различных видов мелиораций. В рассматриваемом случае имеет место мелиорация переуплотненных склоновых земель, которые после рыхления получают новую эволюцию и возможность реализации новых технологических процессов, обеспечивающих глобальную цель повышения урожайности. Приведены оценки эффективности различных способов обработки почв. Рассмотрена содержательность почвенно-мелиоративной агротехники на основе внутрипочвенного рыхления. Показаны данные экспериментальных исследований инновационного глубокорыхлителя ГНЧ-0,6M, включающие сравнительные показатели урожайности ярового ячменя на склоновых землях после обработки почвы предложенным устройством и прототипом. В результате проведенных исследований последействия глубокого рыхления на глубину 60 см выявлено, что для поддержания высокой урожайности посевных культур в климатических и почвенных условиях места проведения мелиоративные мероприятия по глубокому рыхлению на глубину до 0,6 м следует проводить один раз в два года.

A. Mikhaylin, V. Maksimov

\title{
EVALUATION OF TREATMENT EFFICIENCY OF RAIN-FED SLOPING LAND IN THE SOUTHERN DISTRICTS OF THE ROSTOV REGION BY THE INNOVATIVE CHISEL PLOW ГHЧ-0,6M
}

\author{
Key words: chisel plow; chisel; over-compaction; rain-fed lands; slope; accumulation of moisture; yield.
}

\section{Authors' personal details}

1. Mikhaylin Andrey, Candidate of Technical Sciences, Associate Professor, South-Russian State Polytechnic University named after M.I. Platov, e-mail: mih_2005@rambler.ru.

2. Maksimov Valeriy, Doctor of Technical Sciences, Professor, South-Russian State Polytechnic University named after M.I. Platov, e-mail: v_maximov@mail.ru.

The modeling of the events of moisture transfer in the soil uses the concept of porosity, which directly depends on the density and physical and mechanical properties of the soil. The creation of the necessary conditions for water permeability is possible by the relevant working bodies due to the mechanical crumbling of the over-compacted horizons into soil lumps of the appropriate size. An integral indicator of the economic functions of the soil is the biological productivity - yield, which is determined mainly by the use of different types of reclamation. In this case, there is a reclamation of reclaimed slope land, which after loosening receives a new evolution and the possibility of implementing new technological processes providing a global goal of increasing yields. The estimates of the effectiveness of different methods of soil treatment are given. The content of soil-reclamation agricultural engineering on the basis of soil loosening is considered. The data of experimental studies of innovative deep-loosener ГНЧ-0,6M, including comparative indicators of yield of spring barley on slope lands after tillage by the proposed device and prototype are shown. As a result of the studies of the aftereffect of deep loosening to a depth of $60 \mathrm{~cm}$, it was found that in order to maintain a high yield of crops, in climatic and soil conditions of the venue, reclamation measures for deep loosening to a depth of $0,6 \mathrm{~m}$ should be carried out once every two years.

(c) Михайлин А.А., Максимов В.П. 